\title{
A necessária superação do processualismo liberal em tempos de relações virtuais e a busca de respostas corretas para litígios envolvendo direitos transindividuais decorrentes da sociedade em rede ${ }^{1}$
}

\author{
The need to transcend the liberal processualism in times of virtual relationships and the \\ search for correct answers to litigations involving transindividuals rights arising from \\ networked society \\ Cristiano Becker Isaia² \\ Danielli Gadenz \\ Letícia De La Rue Almeida
}

\begin{abstract}
Resumo
Diante das mudanças sociais oriundas da sociedade em rede, o processo civil também precisa estar adequado a esta nova realidade para poder tutelá-la eficientemente. Partindose do processualismo liberal, passando pela investigação da possibilidade de alcance de respostas corretas no ambiente processual, tendo por base a teoria de Ronald Dworkin, a ideia deste trabalho é investigar a possibilidade de alcançar respostas corretas nos litígios que envolvem direitos transindividuais. A matriz teórica adotada foi a fenomenológicohermenêutica, que constitui um "deixar ver" que o fenômeno é essencial para o desvelamento, para que o jurista (que desde-já-sempre tem experiência de mundo antecipada pela pré-compreensão) possa compreender a realidade, abnegada pelo positivismo jurídico e pela metafísica, a partir da tradição em que está inserido e da finitude de seu conhecimento. Os "métodos" de procedimento adotados foram o histórico e o monográfico, o que se justifica pela incursão no direito processual sedimentado desde o século XVII e seguintes, bem como à verificação das condições de possibilidade para a superação dos desafios da jurisdição processual no século XXI.
\end{abstract}

Palavras-chave: processo civil; sociedade em rede; resposta correta; hermenêutica.

\footnotetext{
${ }^{1}$ Artigo recebido em 31 de julho de 2013 e aceito em 28 de março de 2014.

2 Doutor em Direito Público pela Universidade do Vale do Rio dos Sinos (UNISINOS). Professor Adjunto lotado no Programa de Pós-Graduação em Direito (Mestrado) e no Departamento de Direito da Universidade Federal de Santa Maria (UFSM). Professor Adjunto do Curso de Direito do Centro Universitário Franciscano (UNIFRA). Coordenador do NEAPRO/UFSM (Núcleo de Estudos Avançados em Processo Civil da Universidade Federal de Santa Maria - www.ufsm.br/neapro). Autor das obras "Processo civil, atuação judicial e hermenêutica filosófica" (Ed. Jurúa, 2011) e "Processo civil e hermenêutica" (Ed. Juruá, 2012). O presente trabalho é também fruto das pesquisas do autor por ocasião do projeto intitulado Processo civil e $(\mathrm{m})$ crise: o esgotamento do procedimento ordinário na satisfação dos direitos sociais, financiado pela FAPERGS, registrado sob n.12/08808. E-mail: cbisaia@terra.com.br.
} 

em rede

Cristiano Becker Isaia Danielli Gadenz Letícia De La Rue Almeida DOI 10.12957/dep.2014.6922

\begin{abstract}
Given the social changes arising from the network society, the civil procedure must also be appropriate to this new reality to be able protect it efficiently. Starting from the liberal processualism, through investigation of the possibility of achieving the correct answers procedural environment, based on the theory of Ronald Dworkin, the idea of this work is to investigate the possibility of achieving correct answers in cases involving transindividual rights. The theoretical framework adopted was the phenomenological-hermeneutic, which is a "turn up" phenomenon that is essential for the unveiling, that the lawyer (who sincealways-already has world experience anticipated by pre-understanding) can understand the reality, selfless by legal positivism and the metaphysical, from the tradition in which it is inserted and the finitude of his knowledge. The "methods" adopted were the historical and the monographical, which is justified by the incursion in procedural law settled from the seventeenth century onwards, as well as to verify the conditions of possibility for overcoming the challenges of procedural jurisdiction in the XXI century.
\end{abstract}

Key-words: civil process; network society; correct answer; hermeneutics.

\title{
INTRODUÇÃO
}

As mudanças oriundas do surgimento e expansão da internet moldaram uma nova sociedade. Diversos autores, estudiosos da área, como o sociólogo Manuel Castells que denominam o atual modelo social como "sociedade em rede", alertam que os últimos anos do século XX e do início do século XXI representam uma verdadeira revolução da comunicação. Essa nova realidade está presente, hoje, nas tarefas mais simples do dia-a-dia e inserida na vida comum dos indivíduos. Empresas, governos, pessoas e grupos utilizam a internet como difusora de informações, como fonte de pesquisa, como meio de adquirir bens ou, simplesmente, para entrar em contato com outros indivíduos.

No contexto de um novo modelo social, a partir das alterações advindas da sociedade em rede, alteram-se as relações sociais e, em consequência, novos direitos e novas demandas surgem e não raro terminam por ser levadas ao Poder Judiciário. Um exemplo bastante paradigmático refere-se à proteção de dados pessoais dos indivíduos, facilmente violadas num mundo conectado e multimodal como o de hoje. Em uma realidade prática 
A necessária superação do processualismo liberal em tempos de relações virtuais e a busca de respostas corretas para litígios envolvendo direitos transindividuais decorrentes da sociedade em rede

Cristiano Becker Isaia Danielli Gadenz Letícia De La Rue Almeida DOI 10.12957/dep.2014.6922

processual ainda sobremaneira atrelada ao já ultrapassado paradigma liberal, questões como a tutela eficiente e célere à privacidade violada, como no exemplo acima citado, precisam ser postas em pauta. Como tutelar processualmente tal situação, com celeridade e, sobretudo, eficiência, diminuindo os riscos de exposição da pessoa ou do grupo de pessoas que sofreu o dano?

Diante da problemática processual instaurada no que tange à proteção dos direitos, especialmente os transindividuais, no contexto da sociedade em rede, fala-se em respostas corretas, com o amparo da teoria do jusfilósofo norte-americano, Ronald Dworkin. O fato que não pode ser ignorado, quando se trata de uma sociedade interconectada em diversos níveis - sociais, econômicos, etc - é que o paradigma liberal-individualista, base teórica do processo que temos ainda hoje, em pleno século XXI, é insuficiente para a tutela dos litígios envolvendo a sociedade em rede. Assim, o presente artigo, busca, na teoria supracitada, uma condição de possibilidade para a releitura do processo civil atual, em prol de uma tutela ágil e eficiente para tais questões.

O ponto central do trabalho ancora-se no fato de que, o direito, como ciência social e humana, não pode manter-se alheio a tais evoluções, tão fortemente imbricadas na vida em sociedade, que acabam por suscitar litígios envolvendo os mais variados direitos, desde individuais, até coletivos e difusos. Neste âmbito, em especial, o direito processual civil precisa estar em consonância, de modo a possibilitar ao jurisdicionado a prestação de uma tutela ágil e efetiva. Contudo, o processo judicial tradicional, moroso, ordinarizado, sedimentado em valores liberais racionalistas, não se coaduna com a nova realidade decorrente da sociedade em rede, situando-se diante de um novo dilema deflagrado pela necessária readequação à tutela dos novos direitos decorrentes da realidade digital. Daí o questionamento: É possível buscar respostas corretas nos litígios que envolvem direitos transindividuais decorrentes da sociedade em rede?

Uma possível resposta a ele justifica as linhas que seguem.

\section{DO PROCESSO LIBERAL-INDIVIDUALISTA AO PROCESSO SOCIALIZADO}


A necessária superação do processualismo liberal em tempos de relações virtuais e a busca de respostas corretas para litígios envolvendo direitos transindividuais decorrentes da sociedade

em rede

Cristiano Becker Isaia Danielli Gadenz Letícia De La Rue Almeida DOI 10.12957/dep.2014.6922

O processo civil atualmente posto é, sem dúvida, calcado na ideologia racionalista do Estado liberal. Tal atrelamento é efetivo para a tutela de direitos individuais, tais como os de propriedade. No entanto, tal paradigma focado, ainda, em litígios similares àqueles comuns à época da ascensão burguesa, buscando solucionar questões essencialmente importantes à classe, não está preparado para a tutela de direitos transindividuais, cada vez mais postos em discussão no Judiciário, despreparado para garantir-Ihes uma tutela eficiente, como se pretende demonstrar no decorrer deste trabalho.

Inicialmente, é preciso remontar às bases do processualismo atual, buscando as razões que o fazem estar, ainda, voltado a questões próprias dos direitos de primeira geração, essencialmente individuais.

Amparado pela separação dos poderes (Montesquieu) e pela defesa das liberdades individuais (mérito da Revolução Francesa), o Estado liberal pode ser caracterizado como um Estado mínimo. Uma construção fictícia essencial para que a burguesia pudesse exercer seu comércio com o amparo da lei, que tinha no Poder Legislativo a sua garantia de segurança jurídica. Assim, o Poder Judiciário, reduzido a um mero poder subordinado, tinha por função apenas a reprodução da vontade expressa da lei.

Explica Ovídio Baptista da Silva $(1997$, p. 101) que o processo foi adaptado à realidade social e também aos objetivos da classe dominante - burguesia -, isso para que tivesse seus anseios atendidos e suas ações amparadas pela lei mesma, amarrando a teoria da separação dos poderes ao valorizar os ideais de segurança e certeza. Com efeito:

[...] o processo de conhecimento, como processo declaratório, e, além disso, por natureza ordinário - em que a verdade é proclamada, depois de um amplo debate judicial, como resultado de um juízo de certeza, obtido pelo magistrado através da utilização integral dos meios de ataque e defesa pelos litigantes - será indiscutivelmente o instrumento capaz de abrigar essa espécie de filosofia política que tem, na ideologia da 'separação de poderes', sua base de sustentação.

Influenciado pelo pensamento liberal, trata-se de um momento histórico em que cabia ao juiz nada além da reprodução da vontade da lei, dispensando-o da realização de qualquer ato interpretativo. O processo civil, nesse contexto, paulatinamente afasta-se das 
A necessária superação do processualismo liberal em tempos de relações virtuais e a busca de respostas corretas para litígios envolvendo direitos transindividuais decorrentes da sociedade em rede

Cristiano Becker Isaia Danielli Gadenz Letícia De La Rue Almeida DOI 10.12957/dep.2014.6922

ciências da compreensão, aproximando-se das ciências da demonstração, ficando reduzido a uma equação matemática, na medida em que o magistrado, em um rito ordinário fase a fase, buscaria aplicar a lei a um caso concreto, "extraindo" do sistema suas decisões como verdades matemáticas (ISAIA, 2012, p. 19-20). Essa redução do processo ao modelo matematizado buscava garantir exatidão e certeza, ansiadas pela sociedade liberal, legadas da filosofia racionalista.

Ovídio Baptista (2004, p. 115) aduz a uma tentativa de "geometrização" do direito e do processo, assim identificando as amarras sofridas pelo processo civil no ideário liberalracionalista, tornando-se mais uma fórmula matemática de resolução de problemas:

Se investigarmos as raízes ideológicas que sustentam o nosso paradigma, veremos que o Direito moderno, a partir das filosofias do Século XVII, passou a priorizar o valor 'segurança', como exigência fundamental para a construção do moderno "Estado Industrial". [...] Antes de Savigny 'geometrizar' o Direito, criando um 'mundo jurídico', distante das inimagináveis diversidades' do caso concreto e, portanto, da realidade social, Leibniz, dissera, que não apenas o Direito, mas a própria moral, seriam ciências tão demonstráveis, quanto qualquer problema matemático.

Veja-se que o ideário racionalista permeou o processo no decorrer da evolução do Estado Moderno, garantindo a expansão do modo de produção capitalista, que tinha na estrutura estatal a garantia de certeza e segurança ideal para o desenvolvimento da indústria e comércio burgueses. E como se disse, com essa filosofia, quando do surgimento das primeiras codificações (especialmente com o Código Napoleônico), buscou-se afastar os magistrados da tarefa interpretativa. Segue Ovídio Baptista da Silva $(2004$, p. 97) a referir que:

[...] o núcleo da resistência oferecida pelo sistema a ideia de que o Direito seja uma ciência da compreensão, apoia-se nos juízos de verossimilhança, que como dissera Descartes, haverão de ter-se liminarmente como falsos. Se na norma pudesse comportar duas ou mais interpretações válidas e legítimas, como obter segurança procurada pelo nascente Estado Industrial?

O fato é que o liberalismo exerceu grande influência no direito processual civil. A partir da busca pela certeza, a consequente matematização do processo concederia à 
A necessária superação do processualismo liberal em tempos de relações virtuais e a busca de respostas corretas para litígios envolvendo direitos transindividuais decorrentes da sociedade em rede

Cristiano Becker Isaia Danielli Gadenz Letícia De La Rue Almeida DOI 10.12957/dep.2014.6922

magistratura uma função de mera reprodução da lei, essa somente permissiva após cognição exauriente. Essa era a missão do Poder Judiciário. Não havia qualquer compromisso ético ou interpretativo dos juízes ao dizer o direito (ISAIA, 2012, p. 95). O ideário racionalista, calcado na ordem e estabilidade, racionalizou a jurisdição processual, incumbindo-a de proteger o passado legislado e defendê-lo das interferências da política e dos valores que determinavam as reais desigualdades sociais. Consequentemente, a racionalização dos conflitos individuais trouxe consigo uma maior dificuldade de juridicizar conflitos coletivos (LUCAS, 2005, p. 179.), o que atualmente, por óbvio, está em descompasso diante do Estado Democrático de Direito, como será visto a seguir, notadamente a respeito dos direitos transindividuais decorrentes da sociedade em rede.

No aspecto processual propriamente dito, o fato de o sentido vir previamente indicado na lei, por influência do positivismo exegético, revelou, dentre tantas outras, a dificuldade no trato dos juízos de prevenção, na medida em que o juiz somente poderia indicar o que está previamente estabelecido, nunca aplicar a lei a um caso que exigisse uma tutela liminar. Isto porque decisões liminares implicam trabalhar com fatos ainda não ocorridos, na medida em que a decisão judicial se dá com base em juízos de verossimilhança. Contudo, nesse modelo, esses juízos não poderiam ser aceitos uma vez que seriam baseados na vontade do magistrado, e não do legislador, e neste caso, a sentença seria injusta. 0 juiz não poderia considerar fatos ainda não ocorridos, já que sua atividade era meramente declarar o conteúdo da lei, num juízo de cognição exauriente fase a fase, sem trabalhar com a ideia de prevenção (ISAIA, 2012).

O fato é que no contexto do Estado Liberal, a teoria da tripartição dos poderes, ao buscar trazer a neutralidade da atividade jurisdicional, traria reflexos às instituições processuais, relegando o judiciário a uma instância neutra, presa à missão de cumprir mecanicamente as disposições normativas elaboradas pelo legislativo (o que desvelaria a conhecida "subsunção do fato à norma"). Sintetizando o modelo liberal, Nicola Picardi (2008, p. 49) afirma que

[...] o traço comum dos pensadores dessa época, foi, com efeito, sintetizado nos seguintes pontos: a) refutação da silogística clássica que parecia então 
A necessária superação do processualismo liberal em tempos de relações virtuais e a busca de respostas corretas para litígios envolvendo direitos transindividuais decorrentes da sociedade em rede

Cristiano Becker Isaia Danielli Gadenz Letícia De La Rue Almeida DOI 10.12957/dep.2014.6922

um jogo de verbalismos vazios, b) difusão da lógica metodológica cartesiana, c) colocação de temas e características que serão típicas da moderna lógica formal.

Em meio ao contexto da época (séculos XVIII e XIX), percebe-se que a jurisdição no Estado liberal não demonstrava interesse pelas questões sociais, tornando-se reprodutora de uma racionalidade legislativa que pretendia garantir a todo custo a segurança jurídica, orientando sua atuação apenas para viabilizar direitos e liberdades individuais contra a intervenção estatal. Veja-se que num Estado mínimo a participação do direito tende a ser quase que exclusivamente retributiva.

Esse pequeno excurso histórico ilustra que ainda hoje o direito processual civil permanece preso ao paradigma liberal, o que é constatável diante de vários elementos. Mantém-se a reprodução (vide, por exemplo, como se dá, nos Tribunais, a utilização de súmulas e enunciados); a ideologia da ordinariedade; a dificuldade no trato das tutelas de urgência preventivas; a concentração do processo na tutela dos direitos de liberdade e propriedade individual, dentre outros. Alia-se a isso a obsessão pela definição do Direito enquanto ciência que busca o "certo" ou o "errado", "como se o conflito discutido em um processo judicial fosse um cálculo matemático" (FERNANDES, 2010, p. 48).

Em razão desta ausência de preocupação com as questões sociais, a transição entre o Estado liberal e o Estado social é reflexo da busca pela implementação de obrigações positivas ao Estado, alterando a "visão de Estado meramente garantidor de liberdades individuais, para a concepção de um Estado obrigado a prestações sociais tendentes à obtenção de uma maior igualdade social" (PORTO, 2006, p. 58). García-Pelayo (2009, p. 14) enaltece a mudança de paradigma ocorrida na referida transição, dentro do aporte dos direitos fundamentais protegidos pelo Estado (passando-se aos de segunda geração), ao demonstrar principalmente que o ideário de liberdade, para o liberalismo, era exigido pela dignidade da pessoa humana e, com o Estado Social, inverte-se a lógica, passando a dignidade da pessoa humana a ser condição garantidora do direito de liberdade.

Essa revisão dos preceitos que informavam a ordem liberal possibilitou dar conteúdo material aos direitos acima citados, fortalecendo o ente estatal no dever de atuar na 
A necessária superação do processualismo liberal em tempos de relações virtuais e a busca de respostas corretas para litígios envolvendo direitos transindividuais decorrentes da sociedade em rede

Cristiano Becker Isaia Danielli Gadenz Letícia De La Rue Almeida DOI 10.12957/dep.2014.6922

concretização dos direitos, diferentemente da atuação negativa (em que só se sancionava os atos atentatórios aos direitos, sem preocupação com a sua promoção) do Estado liberal (ISAIA, 2012, p. 143). No modelo estatal social o exercício da função jurisdicional assume uma nova roupagem, pois a jurisdicionalidade precisava dar conta da multiplicação dos direitos sociais não atendidos pelo poder executivo.

Isso levaria, no contexto brasileiro da metade ao final do século XX e início do XXI, à massificação das demandas sociais perante o Poder Judiciário, sedimentando o papel do direito enquanto ciência interventora e assistencialista. O Judiciário, que antes não se preocupava com os reflexos de suas decisões na coletividade, restringindo-se à mera aplicação da lei, começa a atuar de forma diferente, não mais como um repressor. Sua atuação passa a ser ativa e diretiva (LUCAS, 2005, p. 181-182). E muito desta tradição do juiz garantidor ainda pode ser notada nos dias atuais, em que, uma demanda por direitos sociais, como por exemplo, o direito à saúde, precisa ser levada ao Judiciário, diante de ineficiência do poder Executivo na consecução de políticas públicas. Assim, o magistrado, indo além do mero silogismo (liberal), passa a atuar como um executor dos direitos negados, pelo Estado, aos cidadãos.

Diante da inefetividade do executivo na realização de políticas públicas de cunho social, coube ao Judiciário "intervir em espaços tradicionalmente reservados ao Executivo para garantir direitos sociais e a se manifestar sobre um novo campo de litigiosidade, marcadamente coletivo e de orientação fortemente política" (LUCAS, 2005, p. 182-183). Impuseram-se novas obrigações aos juízes em face de uma legislação social que se limita, no mais das vezes, a definir a realidade e os princípios gerais dos direitos sociais, sem que estes tenham a possibilidade de serem autoexecutáveis, cabendo aos juízes lhes fornecerem conteúdo, "o que eles podem fazer controlando e exigindo o cumprimento do dever do estado de intervir ativamente na esfera social, um dever que, por ser prescrito legislativamente, cabe exatamente aos juízes fazer respeitar" (CAPELLETTI, 1999, p. 41-42).

O Judiciário passou a (ter de, por força da Constituição Federal de 1988) adotar uma postura ativista, de aproximação com a sociedade, o que exigiria uma atuação mais presente 
A necessária superação do processualismo liberal em tempos de relações virtuais e a busca de respostas corretas para litígios envolvendo direitos transindividuais decorrentes da sociedade em rede

Cristiano Becker Isaia Danielli Gadenz Letícia De La Rue Almeida DOI 10.12957/dep.2014.6922

do magistrado (levando ao tão criticado protagonismo judicial), redefinindo os papéis da atividade jurisdicional. Isso culminou na elevação dos poderes do juiz, o que foi impulsionado processualmente pela transição de um processo liberal, eminentemente escrito e apegado à formalidade da lei, protagonizado pelas partes, a um processo socializado, caracterizado como uma instituição estatal de bem-estar social, no qual o protagonista é o juiz (ISAIA, 2012, p. 151).

Ao Poder Judiciário próprio do Estado Social agrega-se uma característica distributiva ao direito, citada por García-Pelayo (2009. p. 14), conferindo aos direitos pugnados pela sociedade um cunho material, antes inexistente no Estado liberal (de cunho formal). Nesse movimento é que o direito processual disponibiliza à sociedade uma série de mecanismos de proteção (ações diretas de inconstitucionalidade, mandado de injunção, ação declaratória de preceito fundamental, etc.).

Essa verdadeira democratização do acesso à jurisdição levaria a magistratura ao alcance de um poder que teria como base estrutural a consecução dos direitos sociais, antes ignorados pelo Estado. Daí o surgimento da figura do juiz, em processo, assemelhante ao modelo liberal. Capelletti (1999, p. 42) denomina de "juiz criativo", principalmente em razão da carga de discricionariedade decisória na tentativa de implementação de políticas públicopromocionais. Segundo o autor, "é manifesto o caráter acentuadamente criativo da atividade judiciária de interpretação e de atuação da legislação e dos direitos sociais". Reitera, porém, que a diferença entre o papel do juiz criativo e o papel tradicional (dizer a lei - Estado Liberal) é apenas de grau e não de conteúdo, pois entende que toda interpretação é criativa, sendo, algumas vezes, inevitável certo grau de discricionariedade na atividade jurisdicional (1999, p. 42).

François Ost (1993, p. 177) leciona que o juiz próprio do Estado social denomina-se juiz Hércules, já que presente em todas as frentes, indo além do juiz Júpiter (do Estado liberal) ao realizar outras funções, não só reproduzindo a lei. Enquanto Júpiter era um "homem de lei", Hércules é um "engenheiro social”. Para Dierle Nunes (2009, p. 46)

[...] essa visão permitiu um fortalecimento dos poderes judiciais, na grande maioria dos sistemas processuais, com a atribuição da direção do processo 
A necessária superação do processualismo liberal em tempos de relações virtuais e a busca de respostas corretas para litígios envolvendo direitos transindividuais decorrentes da sociedade em rede

Cristiano Becker Isaia Danielli Gadenz Letícia De La Rue Almeida DOI 10.12957/dep.2014.6922

por parte do juiz, entendida não somente no aspecto formal de regular e promover a ordem e o ritmo dos atos do processo, mas também em seu aspecto material, ofertando ao órgão judicial controle e iniciativa oficiosa no recolhimento do material que formará o objeto do juízo sobre o mérito.

Evidentemente, o processo civil acompanhou essa transformação. O que se denomina de socialização processual teve como precursora a literatura de Anton Menger, Franz Klein e Oskar Vön Bülow. O pensamento que conduz suas teorias identifica-se por supervalorizar a posição do magistrado no ambiente processual, diminuindo, por consequência, a participação das partes. Daí a transição, principalmente na Alemanha e Áustria, de um processo liberal, escrito e protagonizado pelas partes, a um processo socializado; um processo caracterizado enquanto "instituição estatal de bem-estar social", como dizia Franz Klein, rumando a uma estrutura processual caracterizada por uma imponente oralidade, onde o protagonista é o juiz, dado o aumento de seus poderes. Tratase, como leciona Dierle Nunes, da atribuição da direção do processo ao juiz, tanto no aspecto formal da regularidade dos atos processuais quanto no aspecto material, este atinente ao controle e iniciativa oficiosa no recolhimento do material que formará seu convencimento (NUNES, 2009, p. 46).

Como esse processo se desenvolve diante dos "novos" direitos, principalmente os de terceira geração, de titularidade coletiva ou difusa? É isso que se propõe a investigar na próxima seção.

\section{O PROCESSO E A TUTELA DOS DIREITOS TRANSINDIVIDUAIS DECORRENTES DA SOCIEDADE EM REDE}

O avanço tecnológico ocorrido no final do século XX e meados do século XXI tem como protagonista a internet, a rede mundial de comunicação, que a seu modo revolucionou a sociedade. Essa tecnologia operou uma transformação: a sociedade passou da era industrial para a era da informação, que tem por característica essencial tratar-se de um sistema social no qual a riqueza econômica e a concentração de poder cultural, militar ou político têm por pressuposto o controle e o processamento da informação. Por estas 
A necessária superação do processualismo liberal em tempos de relações virtuais e a busca de respostas corretas para litígios envolvendo direitos transindividuais decorrentes da sociedade em rede

Cristiano Becker Isaia Danielli Gadenz Letícia De La Rue Almeida DOI 10.12957/dep.2014.6922

razões, Castells (1999, p. 82) denomina este momento histórico como Sociedade Informacional ou Sociedade em Rede.

No contexto da sociedade informacional, entendendo a terceira geração de direitos humanos como complementadora das fases anteriores - complementando as liberdades civis e políticas da primeira e os direitos econômicos, sociais e culturais da segunda -, Pérez Luño (2012, p. 17) justifica que os direitos de terceira geração são também denominados "novos direitos", "direitos de solidariedade", "direitos da era tecnológica", "direitos emergentes", etc. Isto não significa, porém, que o termo "novos" designe que os direitos das gerações anteriores são velhos, apenas denota que existem novas circunstâncias delimitando seu exercício (PÉREZ LUÑO, 2012, p. 18).

No que tange a esses "novos" direitos, Pérez Luño (2012, p. 18-20) entende que a solidariedade figura como um valor-guia para sua compreensão, defendendo a denominação "direitos de terceira geração" como a mais compreensível no contexto de um Estado constitucional de direito, assim como a primeira é originária do Estado liberal e a segunda do Estado social. Ressalta que o rol dos direitos de terceira geração não é fechado, devendo ser encarado como um marco referencial acerca das demandas atuais que afetam os direitos e liberdades da pessoa humana. Isso porque, para ele, a terceira geração de direitos humanos contribui para redimensionar a imagem do homem no ambiente social enquanto sujeito de direitos, pois dá novas condições de exercício político (PÉREZ LUÑO, 2012, p. 25).

Pérez Luño aponta para a dicotomia decorrente da revolução tecnológica: por um lado, as novas tecnologias produziram importantes melhorias na condição de vida da humanidade, reforçando, em alguns casos, o exercício de alguns direitos; por outro, o abuso das novas tecnologias representam uma grave ameaça para as liberdades, exigindo a formulação de novos direitos, atualização ou adequação do meios de garantia dos direitos já existentes (2012, p. 20).

Existem discussões acerca da relevância na consideração desses direitos como direitos humanos, ao passo que estão inseridos em uma realidade de debilidade e imprecisão de instrumentos de garantia, o que compromete seu status normativo e também 
A necessária superação do processualismo liberal em tempos de relações virtuais e a busca de respostas corretas para litígios envolvendo direitos transindividuais decorrentes da sociedade em rede

Cristiano Becker Isaia Danielli Gadenz Letícia De La Rue Almeida DOI 10.12957/dep.2014.6922

a proteção dos direitos consagrados nas gerações anteriores. No entanto, Pérez Luño (2012, p. 25-26) entende que negar às demandas decorrentes das novas tecnologias a possibilidade de alcançar a posição de direitos humanos seria desconsiderar o seu caráter histórico, privando-os de uma tutela jurídica que se faz necessária.

As novas tecnologias permitem a humanidade estabelecer comunicação em escala planetária quase que instantaneamente. A internet é a grande revolução do nosso tempo, e seus efeitos, como dito, se projetam à esfera das liberdades. Cita-se, por exemplo, a gama de informações dos indivíduos que se encontram na rede, e que podem ser utilizadas com as mais diversas finalidades. A internet "converte informações parciais e dispersas em informações em massa e organizadas", o que enseja a urgência na regulamentação desse meio (PÉREZ LUÑO, 2012, p. 23).

A questão é que os direitos de terceira geração também exigem novas formas de tutela diante do reconhecimento de alguns novos direitos, como o da liberdade informática e o da autodeterminação informativa. De acordo com Pérez Luño (2012, p. 28-29), Peter Häberle traz o ideário de status activus processualis como o reconhecimento da faculdade de cada indivíduo em participar ativamente e assumir sua própria responsabilidade nos procedimentos que a afetam. Um fator chave para que os Estados assegurem o exercício pleno de todas as liberdades. Esse status significa dar valor à autodeterminação do sujeito na sociedade em que está inserido (citam-se aqui sistemas como o do habeas data e do Ombudsman).

No caso brasileiro, em que pese a Constituição Federal de 1988 ter estabelecido uma série de direitos e garantias aos cidadãos, muito pouco é concretizado pelo Estado, o que leva um sem-número de pessoas a buscarem o Judiciário a fim de ver seu direito assegurado. Em tempos de sociedade em rede, mais e mais demandas aparecem, principalmente aquelas envolvendo direitos coletivos e transindividuais, como a proteção da privacidade dos usuários da internet, que tem o direito a não serem indevidamente espionados tanto pelos Estados quanto por empresas privadas. 
A necessária superação do processualismo liberal em tempos de relações virtuais e a busca de respostas corretas para litígios envolvendo direitos transindividuais decorrentes da sociedade em rede

Cristiano Becker Isaia Danielli Gadenz Letícia De La Rue Almeida DOI 10.12957/dep.2014.6922

O problema para este estudo, a despeito da tutela desses direitos, que por excelência são transindividuais, ou seja, vão além da esfera individual, atingindo outros indivíduos que por vezes são indeterminados, está no fato de que os instrumentos processuais que se mostravam suficientes para a solução dos litígios individuais têm diminuída, agora, a sua funcionalidade. Daí a importância em reaproximar o processo do direito material, rompendo-se com o paradigma da jurisdição processual liberal em direção a um modelo de processo condizente com a Constituição Federal de 1988, ou seja, com os valores democráticos, "onde a jurisdição é chamada para concretizar valores constitucionais ordenando a superação do individualismo processual” (FERNANDES, 2010, p. 19).

Um modelo em que todos os procedimentos sigam as garantias previstas na Carta Magna brasileira. Isso não significa que a relação entre tempo, procedimento, efetividade e eficiência processual seja necessariamente a mesma que se apresenta em outras famílias de processo, como no processo penal ou administrativo, por exemplo. Mas significa que, quando se fala numa leitura constitucional de processo, as garantias processuais constitucionais, mesmo que com outras roupagens, devem estar presentes. Esses são os verdadeiros desafios da jurisdição processual no século XXI.

Daí falar num processo civil antimoderno, que ultrapasse um modo de produção do conhecimento a partir de universalizações, de alcance a certezas absolutas diante de demonstrações lógicas (o que marcou a fase do liberalismo processual). Um processo também capaz de romper com a lógica moderna da supervalorização da proteção dos direitos de primeira geração, estes relacionados às liberdades individuais, à propriedade, à posse, etc. Não se trata de renunciar a proteção processual desses direitos, mas reconduzir o olhar para os direitos de índole coletiva e difusa, que merecem um tratamento diferenciado pelo processo civil no século XXI.

Numa sociedade conectada e acelerada, permeada pelas relações envolvendo as tecnologias digitais, o Estado ainda encontra muita dificuldade em tratar das novas demandas envolvendo essas questões. Nesse mesmo sentido, também o atual sistema processual civil, não está alinhado às exigências dos novos direitos oriundos da sociedade 
A necessária superação do processualismo liberal em tempos de relações virtuais e a busca de respostas corretas para litígios envolvendo direitos transindividuais decorrentes da sociedade em rede

Cristiano Becker Isaia Danielli Gadenz Letícia De La Rue Almeida DOI 10.12957/dep.2014.6922

em rede. O processo civil necessita de uma reconstrução para garantir aos seus jurisdicionados uma tutela ágil e eficiente. Os institutos clássicos do processo de há muito se mostram impotentes para a tutela dos direitos metaindividuais, especialmente os direitos típicos de uma sociedade complexa e em rede, o que implica na necessidade de que o processo civil esteja atento ao paradigma do Estado Democrático de Direito, superando o paradigma racionalista e os valores liberais individualistas a que permanece atrelado (ESPÍNDOLA; CUNHA, 2011, p. 89). Isto somente poderá ocorrer substituindo a atual concepção processual cartesiana por uma compreensão hermenêutica que consagre os valores constitucionais.

E não se pense que o novo código de processo civil que está por vir alterará esse quadro. Nesse novo paradigma que se instaura, Isaia (2012, p. 262, grifo do autor) apresenta a problemática instaurada no âmbito do processo civil: "o processo civil do século XXI carece de um pensar a partir do novo modelo de organização social que ser apresenta". Afinal, o direito tem o dever de acompanhar a realidade, devendo manter-se em constante adaptação às situações sociais e jurídicas que se apresentam, devendo a atuação do Poder Judiciário deve ser norteada por uma prestação jurisdicional redemocratizada, em observância aos princípios do Estado Democrático de Direito.

Não são poucos os desafios para a construção de um novo sistema processual civil no século XXI, ainda mais quando se está prestes a receber um "novo" código de processo, que medularmente continua comprometido com ideais antidemocráticos. Isso é facilmente percebido quando o processualismo confronta-se com um código que trará sérias dificuldades no trato das ações coletivas, que mais do que nunca supereleva o papel solipsista do juiz e que dá continuidade na aposta à procedimentalidade ordinária e plenária. Ainda: que parte do pressuposto, pretendendo fazer crer que assim dará coerência e integridade ao sistema, que a estabilização da jurisprudência firmada nos tribunais superiores é garantia de incremento de segurança jurídica, achando que com isso salvará o processo do "desvirtuamento" da atividade jurisdicional de primeiro grau (GRESTA, 2012, p. 225). 
A necessária superação do processualismo liberal em tempos de relações virtuais e a busca de respostas corretas para litígios envolvendo direitos transindividuais decorrentes da sociedade em rede

Cristiano Becker Isaia Danielli Gadenz Letícia De La Rue Almeida DOI 10.12957/dep.2014.6922

Essa obsessão pela padronização decisória "de cima a baixo" proposta pelo "novo" código nem de perto significa o que alguns autores, em especial Ronald Dworkin, vêm trabalhando à luz da necessidade de se construir decisões judicias coerentes e íntegras, como se verá na seção seguinte. Como bem alerta Roberta Maia Gresta, esse tipo de proposta leva a uma total inversão dos fatores da cultura jurídica, subvertendo o processo como instituição democrática (2012, p. 226).

Olvidar que o processo é um espaço discursivo e que ocupa um lugar importante na construção de uma sociedade democrática só contribui contra a integridade do sistema jurídico. E é isso que acabará ocorrendo diante da universalização de padrões decisórios, que a seu modo vem sendo a principal ferramenta na construção de um sistema que funciona "por atacado", no pretenso ideário de conferir, dessa forma, segurança jurídica.

\section{O PROCESSO E A TESE DA RESPOSTA CORRETA DE RONALD DWORKIN}

$\mathrm{Na}$ intenção de pensar o processo civil para além do esquema sujeito-objeto, aproximando juiz, partes, comunidade, etc. (expressões da democratização processual), aliado ao objetivo de compreender o sistema processual de forma assemelhante a um método (expressão da sumarização processual), mas sim diante de novos ambientes de satisfação dos direitos fundamentais, principalmente os de terceira geração, decorrentes de uma sociedade em rede, é imperioso questionar: Como ultrapassar uma concepção que há séculos desloca o processo para o âmbito dos "instrumentos", das "ferramentas" à disposição do magistrado e seu subjetivismo? É possível alcançar respostas corretas em processo civil, principalmente na tutela de direitos transindividuais?

No plano da teoria do direito, Dworkin já questionou sobre a possibilidade da existência de respostas corretas principalmente diante de casos controversos. Segundo o jusfilósofo norte-americano, é possível falar em respostas corretas em direito dependendo do como se compreende a afirmação de que uma proposição em direito é bem fundada, se faz parte da melhor justificativa que se pode oferecer para o conjunto de proposições jurídicas tidas como estabelecidas (2005, p. 213). 
A necessária superação do processualismo liberal em tempos de relações virtuais e a busca de respostas corretas para litígios envolvendo direitos transindividuais decorrentes da sociedade em rede

Cristiano Becker Isaia Danielli Gadenz Letícia De La Rue Almeida DOI 10.12957/dep.2014.6922

O problema está na discricionariedade judicial. Essa seria a manifestação mais sofisticada de positivismo na atualidade. ${ }^{3}$ Isto porque, como já mencionado, a ineficácia na execução de políticas públicas acaba por sobrecarregar o Judiciário de demandas sociais, culminando no "juiz Hércules" que, indo além do que lhe é constitucionalmente atribuído, invade a esfera do Executivo, a fim de promover a consecução das políticas não realizadas pelo Poder Público. Ocorre que, ao protagonizar o processo, este magistrado atua com discricionariedade, ante sua preocupação em garantir a execução das citadas políticas, o que é contrário ao ideário processual democrático, que aqui se defende.

Veja-se que Dworkin trabalha com dois parâmetros de discricionariedade: uma em sentido fraco e outra em sentido forte (ISAIA, 2012, p. 154). A discricionariedade no sentido fraco seria a capacidade de julgar contramecanicamente quando o contexto não é esclarecedor. Já no seu sentido forte, a discricionariedade estaria relacionada diretamente ao controle das decisões (DWORKIN, 2007, p. 51). É neste sentido (forte) que se encontra o problema, já que, ao não encontrar no sistema jurídico, nos casos difíceis, resposta ao caso concreto, o juiz deveria decidir discricionariamente, ignorando inclusive a carga

\footnotetext{
${ }^{3}$ Na obra "Levando os Direitos a sério", Dworkin (2007) desenvolve uma nova teoria dos direitos, buscando afastar os juízes da teoria positivista, de modo que utilizem outros parâmetros para proferir suas decisões, não dando margem à discricionariedade. Ao se debruçar sobre um caso difícil, o juiz (aqui denominado Hércules) tem o dever de descobrir a intenção da lei. Primeiramente, ele defende a análise da Constituição do país, como forma de entender a filosofia política que permeia e embasa os direitos dispostos, pois, na visão do autor (2007, p. 166), "a Constituição estabelece um sistema político geral que é justo o bastante pata que o consideremos consolidado por razões de equidade". A seguir, passando ao exame da lei vinculada ao caso em debate, entende que o juiz deve perguntar-se quais teriam sido os argumentos de política que levaram o legislativo a promulgar a lei e, por fim, analisando os precedentes, o juiz precisa levar em consideração os argumentos de princípios determinantes para as decisões tomadas anteriormente (DWORKIN, 2007, p. 165171). De acordo com tais elementos, refere Dworkin $(2005$, p. 101) que o juiz deve tomar decisões de princípio e não de política, de modo a verificar quais direitos as pessoas possuem perante o ordenamento constitucional nacional, não sendo responsável por decidir em nome da moralidade política ou do bem-estar geral - função que cabe ao Poder Legislativo, na formulação de leis, quando toma decisões de política, respeitando, assim, a democracia. Desse modo, a interpretação realizada por Hércules é composta por três etapas: a primeira - préinterpretativa - dá-se com a identificação das regras e padrões que foram considerados nas decisões anteriores, sendo que, mesmo aqui deve ocorrer certa interpretação; a segunda etapa - interpretativa consiste em encontrar uma justificativa geral para os principais elementos das decisões precedentes, constituindo uma argumentação acerca da possibilidade de utilização da mesma prática anterior; e, por fim, a terceira etapa - pós-interpretativa ou reformuladora - na qual Hércules ajusta o que entende realmente melhor servir de justificativa para a prática que pretende aplicar (aquela aceita na etapa interpretativa) (DWORKIN, 1999, p.. 81-82).
} 
A necessária superação do processualismo liberal em tempos de relações virtuais e a busca de respostas corretas para litígios envolvendo direitos transindividuais decorrentes da sociedade em rede

Cristiano Becker Isaia Danielli Gadenz Letícia De La Rue Almeida DOI 10.12957/dep.2014.6922

principiológica do direito.

Leciona Dworkin (2007, p. 65) que o juiz discricionário deixaria de debater-se em prol de suas conviç̧ões, sua subjetividade, com todo um conjunto de padrões que estão em transformação, desenvolvimento e mútua interação, os quais dizem respeito à responsabilidade institucional, à interpretação das leis, à relação de todos esses fatores com as práticas morais contemporâneas e com um grande número de outros padrões do mesmo tipo.

Ovídio Baptista da Silva também enfrenta a questão da discricionariedade judicial. Para ele, a teoria da antidiscricionariedade de Dworkin mantém relação com a diferenciação que o jusfilósofo faz de regras e princípios, no sentido de que as regras são normas aplicáveis na forma do "ou tudo ou nada", pois elas são aplicáveis apenas quando se está diante de situações pré-estabelecidas pela norma. Já os princípios são normas que não firmam uma consequência jurídica precisa diante de uma circunstância igualmente precisa, pois expressam considerações de justiça, equidade, ou outras dimensões da moralidade. Assim, os princípios não estabelecem uma solução inequívoca para o caso concreto, o que é papel das regras (SGARBI, 2009, p. 151).

O ponto em comum do pensamento de Ovídio Baptista e de Dworkin é o desejo por um juiz responsável, que garanta a coerência e a integridade de suas decisões. Daí a premente necessidade, muito enfatizada por Ovídio Baptista, da fundamentação das decisões. Evidentemente, no âmbito do direito processual civil essa questão assume uma posição de destaque, principalmente porque quando se está a tratar de processo também se está a tratar do como as decisões devem ser tomadas.

Essa é uma preocupação flagrante em praticamente todo o legado de Ovídio Baptista, que sempre viu na necessidade de fundamentação das decisões uma (constitucional) exigência dos sistemas políticos contemporâneos em ampliar as bases de um regime democrático participativo, fator também justificável pela necessária superação de uma formação jurídica dogmática em que o direito acabou sendo seduzido pelos princípios epistemológicos das ciências naturais e matemáticas. 
A necessária superação do processualismo liberal em tempos de relações virtuais e a busca de respostas corretas para litígios envolvendo direitos transindividuais decorrentes da sociedade em rede

Cristiano Becker Isaia Danielli Gadenz Letícia De La Rue Almeida DOI 10.12957/dep.2014.6922

O processo civil, para o saudoso professor, deveria ser pensado como uma realidade inconclusa; uma realidade a ser instituída pelo ato jurisdicional que o encerra, já que se está sempre em presença de uma partícula da história humana, o que leva ao problema das decisões a uma necessidade: o dever de serem suficientemente razoáveis, resultantes, quase sempre, de um compromisso difícil entre valores, às vezes inconciliáveis, cuja coexistência lhe cabe organizar. Isso justifica porque Ovídio Baptista sustentou uma compreensão hermenêutica do direito processual civil, o que impõe pensar o processo, a lei, o fato, etc., no respectivo contexto histórico e político.

Dworkin (1999, p. 275) sustenta algo muito semelhante a isso. Compreende o direito como um romance em cadeia, sendo cada decisão dos juízes um capítulo do romance. Aduz que eles devem levar sempre em conta o capítulo anterior para que seja escrito o próximo, de modo a possuir integridade, ou seja, o juiz "deve tentar criar o melhor romance possível como se fosse obra de um único autor, e não, como na verdade é o caso, como produto de muitas mãos diferentes" (DWORKIN, 1999, p. 276), exigindo que o autor (juiz) tenha uma visão geral da obra (precedentes), o que não o impede de encontrar erros ou inadequações ao longo da obra (DWORKIN, 1999, p. 277).

Dworkin explica que o direito exige integridade não no sentido de que as decisões tentem estender as leis ou princípios aplicados séculos antes às decisões que vão proferir, mas, sim, no sentido de que a integridade "exige uma coerência de princípios mais horizontal do que vertical, ao longo de toda uma gama jurídica que a comunidade agora faz vigorar" (DWORKIN, 1999, p. 273). Isso significa que os direitos e deveres decorrentes das decisões passadas, os princípios então utilizados, devem justificar o conteúdo das novas decisões, sendo que o direito como integridade começa no presente, voltando-se ao passado apenas na medida em que o enfoque contemporâneo assim o exija (DWORKIN, 1999, p. 274).

Orlando Faccini Neto (2011, p. 32) explica que a integridade exige dos juízes uma postura decisória que trate o sistema de normas como um conjunto coerente de princípios e, com eles, interpretem essas normas, descobrindo normas implícitas sob as normas 
A necessária superação do processualismo liberal em tempos de relações virtuais e a busca de respostas corretas para litígios envolvendo direitos transindividuais decorrentes da sociedade em rede

Cristiano Becker Isaia Danielli Gadenz Letícia De La Rue Almeida DOI 10.12957/dep.2014.6922

explícitas. Assim, por exigência da integridade, as normas públicas expressam um sistema único de justiça e equidade, estabelecendo que "a decisão judicial seja determinada por princípios, não por acordos, estratégias ou acomodações políticas" (FACCINI NETO, 2011, p. 31).

Com isso é possível dizer que as respostas corretas no âmbito do direito processual encontram-se com a própria fundamentação das decisões, o que impõe, para uma compreensão hermenêutica do processo, a inserção do intérprete no contexto da controvérsia na busca pela significação do fato submetido à apreciação da jurisdição processual. Isso lembra Heidegger, para quem somente há ser quando se der a compreensão do ser; somente há ser quando há ser-aí, o que pressupõe o lugar ocupado pelo magistrado na relação processual e sua consciência da história efeitual.

Com Heidegger é possível sustentar (tal qual Lenio Streck em Verdade e Consenso) que o encontro de respostas corretas passa a ser uma necessidade, devendo passar pelo reforço do locus da situação concreta processual (onde o ser é compreendido pelo ser-aí), o que leva a uma revalorização da jurisdição de primeiro grau num trabalho de simbiose entre democratização e sumarização. Assim aproximam-se partes, juiz, sociedade, etc., para fazer valer os ditames da Constituição de 1988.

A resposta correta, portanto, só pode ser dada no caso concreto. No contexto da sociedade em rede, a mudança de paradigma acima referida, capaz de modificar o padrão das decisões, é facilmente detectada, especialmente quando nos damos conta da herança racionalista ainda presente no processo civil atual. Em face de toda a digressão teórica aqui apresentada, resta claro que o processo necessita da "construção de um novo paradigma jurídico-interpretativo substancial, ancorado na atividade interpretativa constitucionalmente adequada e responsável do intérprete que, através do processo enquanto ser constitucional, atribuirá significado aos fatos" (ISAIA; HOFFMAN, 2012).

A questão está em que definitivamente é impossível encontrar respostas corretas em processo civil sem que o fato concreto e o direito material-constitucional sejam evidentemente levados em consideração. O contrário seria (o que vem infelizmente 
A necessária superação do processualismo liberal em tempos de relações virtuais e a busca de respostas corretas para litígios envolvendo direitos transindividuais decorrentes da sociedade em rede

Cristiano Becker Isaia Danielli Gadenz Letícia De La Rue Almeida DOI 10.12957/dep.2014.6922

ocorrendo desde Oskar Von Bulow) sobrelevar o procedimento, a ritualização, que por ser fundamentalmente um método é o que vem justificando o cometimento de decisionismos judiciais, haja vista a própria deficiência fundamentativa com que comumente se revestem as decisões, fruto do distanciamento entre sujeito e coisa, produto da ordinariedade. Claro: "a" resposta correta no ambiente processual não pode depender diretamente do procedimento. Esta, aliás, foi a principal crítica que Lenio Streck, no plano da teoria do direito, estendeu a Habermas e à sua teoria do discurso e do agir comunicativo (2007, p. 286).

Ao se visitar a obra de Habermas, principalmente na terceira fase habermasiana, é possível concluir que realmente não há condições em se sustentar a tese da busca de respostas corretas (aplicada ao processo civil) através da teoria discursiva do direito. No livro Direito e democracia: entre facticidade e validade, ainda que Habermas (1997, p. 181) nele demonstre uma proposta adstrita à filosofia da linguagem, um rompante à metafísica clássica, irá sustentar que a questão da interpretação encontra-se diretamente vinculada ao método procedimental, o que garantiria a própria legitimidade do ato interpretativo.

Em sentido contrário, para este estudo, o encontro "da" resposta correta em processo guarda relação com a hermenêutica filosófica, uma vez que não há método para se chegar a ela, mas sim a condição de ser-no-mundo em que se localiza e age o intérprete, o que pressupõe a pré-compreensão da Constituição do país e do plano fático que se apresenta à jurisdição processual, até mesmo porque a compreensão, principalmente com Heidegger, é um "ver entorno", e na fundamentação reside o "ter prévio".

Não se trata de um processo de extração de sentido do fato (do caso concreto), um produto da ordinariedade, mas um processo de significação do fato (que também é desvelamento, aletheia), que justamente por ser um fato é também uma categoria hermenêutica que pode se transfigurar no curso do tempo. Esse processo de significação (desvelamento) do fato não pode ocorrer em um isolamento de sentido, devendo ser direta e umbilicalmente relacionado ao sistema jurídico, principalmente o constitucional, que não é um elemento separado do intérprete, mas que faz parte (deve fazer) de seu existencial, sob 
A necessária superação do processualismo liberal em tempos de relações virtuais e a busca de respostas corretas para litígios envolvendo direitos transindividuais decorrentes da sociedade em rede

Cristiano Becker Isaia Danielli Gadenz Letícia De La Rue Almeida DOI 10.12957/dep.2014.6922

pena dele renunciar ao Estado democrático de direito. Tudo isso, evidentemente, está relacionado a uma situação concreta e a sua inserção pelo intérprete. À sua faticidade e historicidade.

Dito de outro modo: para esta pesquisa, os sentidos dados aos fatos, quando levados ao conhecimento da jurisdição processual, são atribuídos a partir da faticidade em que está inserido o intérprete (o ser-aí), não a partir de conceitualizações ou rotulações. Uma significação que já é aplicação, e que assim não renuncia a singularidade. $O$ fato levado ao plano do processo civil não é um dado objetivo, algo separado do intérprete, distante da circularidade hermenêutica.

O acesso ao fato e o processo de atribuição de sentido só se dá quando o intérprete nele mergulha (eis a hermenêutica do ser-aí, a compreensão do ser-no-mundo), o que gadamerianamente falando encontra lugar na antecipação de sentido (pré-compreensão) e na circularidade hermenêutica (inserção na situação hermenêutica). O que deve ficar claro é que em nenhum momento se deve confundir a necessidade, no plano do processo, do encontro "da" resposta correta, com a clássica visão de processo enquanto instrumento desvelador de verdades eternas ou absolutas. Ainda que a relação entre processo, verdade e verossimilhança mereça um tratamento especial, é possível referir que hermeneuticamente (no cariz filosófico) só é possível falar em verdades no sentido ontológico, ligados à possibilidade de elaborar juízos legítimos, dependentes da pré-compreensão do intérprete.

Dessa forma, é possível falar em resposta correta em processo enquanto resposta hermeneuticamente correta, que poderá ser verdadeira se por verdadeiro der-se a possibilidade do ser-aí (o intérprete da norma, o juiz) apropriar-se de pré-juízos autênticos no instante de sua aproximação com o plano fático (daquele caso) e com a Constituição Federal, considerando que a verdade em processo é sempre uma verdade hermenêutica sujeita às condições de temporalidade e compreensão, e que, portanto, almeja uma atuação jurisdicional para além do solipsismo.

Essa resposta hermeneuticamente correta em processo encontra neste trabalho a aproximação a um repensar da atividade processual sob o viés do perfil hermenêutico- 
A necessária superação do processualismo liberal em tempos de relações virtuais e a busca de respostas corretas para litígios envolvendo direitos transindividuais decorrentes da sociedade em rede

Cristiano Becker Isaia Danielli Gadenz Letícia De La Rue Almeida DOI 10.12957/dep.2014.6922

filosófico e, em pé de igualdade, com a teoria de Dworkin. A condição de possibilidade está em afinar o processo civil com locais de sumarização processual, democraticamente preparados ao enfrentamento de uma complexidade e contingência sociais que revelam a necessidade do desvelamento do ser dos entes dos direitos fundamentais.

E mais: de um processo civil relacionado a um judiciário difundido, que aprenda a reconhecer as diferenças através de um poder compartilhado por todos os sujeitos que atuam no processo, contrapondo-se ao modelo metafísico-objetificante presente no rito fase a fase ordinário em prol de uma nova concepção de jurisdição processual difundida democrático-substancialista, aberta aos impulsos jurisprudenciais e aos clamores da sociedade para ultrapassar o formalismo processual e cumprir a Constituição, tendo-a como limite de atuação. Um exemplo de como introduzir os demais sujeitos que atuam no processo seria, no caso de direitos transindividuais, a realização de audiências públicas ao longo do processo, nos quais membros de diferentes segmentos da sociedade civil interessados no julgamento da causa pudessem prestar sua colaboração.

Uma abertura que a própria constitucionalização exige diante do resultado da história e da cultura. Um processo pluralista em que os segmentos da sociedade terão participação ativa na construção do ato jurisdicional, rompendo com o subjetivismo interpretativo para satisfazer valores democráticos, legitimando a própria atuação da magistratura. Enfim, um novo agir processual sumário que atenda liminarmente (mas democraticamente) as pretensões de direito material-constitucional; que compreenda o processo enquanto fenômeno, deixando visualizar sua fenomenologia enquanto condição para o desvelamento e que pressuponha a necessidade de impedir que o intérprete do caso não se desligue do mesmo pela sequência fase a fase do procedimento ordinário.

Assim, "o processo civil, enquanto processo hermeneuticamente constitucional(izado), propiciará ao intérprete um encontro com o sentido constitucional de verdade dos fatos apresentados" (ISAIA, HOFFMAN, 2012). Daí a premente necessidade de uma releitura das normas jurídicas processuais aos princípios constitucionais, na medida em que somente com a devida interpretação dos ditames e princípios constitucionais será 
A necessária superação do processualismo liberal em tempos de relações virtuais e a busca de respostas corretas para litígios envolvendo direitos transindividuais decorrentes da sociedade em rede

Cristiano Becker Isaia Danielli Gadenz Letícia De La Rue Almeida DOI 10.12957/dep.2014.6922

possível almejar a efetivação dos direitos, aplicando seus princípios na readequação da legislação ao conteúdo e ao ideário do constituinte.

Deste modo, defende-se que a busca por respostas corretas, amparadas pelos princípios constitucionalmente postos, a partir da busca pela coerência trazida por Dworkin, como meio de evitar o protagonismo judicial do juiz Hércules, é fundamental para a solução dos litígios transindividuais oriundos da realidade social "em rede". Utilizando-se de um processo ainda atrelado aos ideais individualistas, a atuação sempre conforme a Constituição Federal deve ser realizada como forma de evitar o protagonismo judicial para além dos poderes do Judiciário. Assim, no contexto atual, a busca pela efetividade, mesmo que em procedimentos ainda não totalmente adequados, a filtragem constitucional deve ser sempre observada, até que o processo civil seja efetivamente adaptado à nova realidade.

Vislumbra-se, portanto, a necessidade de superar o paradigma processual racionalista, se dá com a inserção de uma dimensão hermenêutica à apreciação judicial do caso concreto. É imprescindível que haja um real rompimento na atual concepção de processo civil, de modo a inserir no plano jurisdicional o aporte hermenêutico. Somente assim será possível alcançar uma tutela processual desprendida do paradigma racionalista de dependência positivista.

É importante ressalvar que a proposta deste estudo não pretende por fim ao procedimento ordinário de cunho liberal, que é suficiente para a tutela de direitos de cunho individual. O defendido aqui é a necessidade de adequá-lo à tutela dos direitos transindividuais oriundos da sociedade em rede.

\section{CONCLUSÃO}

O processo civil brasileiro encontra-se num momento extremamente paradigmático. Invariavelmente, sofre influências da sociedade informacional ou "sociedade em rede" (Manuel Castells), e precisa adaptar-se à realidade dos novos meios de comunicação, pois 
A necessária superação do processualismo liberal em tempos de relações virtuais e a busca de respostas corretas para litígios envolvendo direitos transindividuais decorrentes da sociedade em rede

Cristiano Becker Isaia Danielli Gadenz Letícia De La Rue Almeida DOI 10.12957/dep.2014.6922

ainda permanece preso a dogmas oriundos do século XVIII, essencialmente liberais. Estes fatores dificultam que, no âmbito processual, a tutela seja efetiva.

No que tange às relações oriundas da sociedade em rede, especialmente relacionadas a direitos transindividuais, o atual processo civil não consegue garantir uma tutela adequada em razão das amarras racionalistas, que o fazem buscar a verdade da lei pelo juiz como um pressuposto matemático, que impede a concretização de um ideário processual democrático. O paradigma racionalista, efetivo para litígios envolvendo direitos essencialmente individuais, precisa ser desconstruído para a tutela de direitos transindividuais, pois estes exigem uma atuação diferente do judiciário, especialmente que o magistrado, ao invés de se afastar do caso concreto, passe a se relacionar com o processo horizontalmente. Desse modo, é necessário que o processo civil se adapte a essa nova realidade social, permitindo que o intérprete final encontre as respostas para as novas controvérsias dentro de um parâmetro condizente com os problemas trazidos pela sociedade em rede.

Portanto, como meio de efetivar o ideário democrático do processo preconizado pela Constituição Federal de 1988, é necessário inserir no processo, a matriz filosófica, permitindo ao magistrado a atuação com um viés interpretativo, redefinindo o atual processo civil. Aí é que a busca por respostas corretas, essenciais para a adequada relação e fundamentação das decisões com os princípios constitucionais, evitando discricionariedade judicial, superando o paradigma racionalista e adequando o processo aos litígios transindividuais decorrentes da sociedade em rede.

\section{REFERÊNCIAS}

BONAVIDES, Paulo. Do Estado Liberal ao Estado Social. 3. ed. Rio de Janeiro: Fundação Getúlio Vargas, 1972.

CAPELLETTI, Mauro. Juízes Legisladores? Tradução de Carlos Alberto Álvaro de Oliveira. Porto Alegre: Sérgio Fabris, 1999.

CASTELLS, Manuel. A sociedade em rede: a era da informação: economia, sociedade e cultura. V. 1. São Paulo: Paz e Terra, 1999. 

em rede

Cristiano Becker Isaia Danielli Gadenz

CHUEIRI, Vera Karam de. Ronald Dworkin. In: BARRETO, Vicente de Paulo (Coord.). Dicionário de Filosofia do Direito. São Leopoldo: Editora Unisinos, 2006. p. 259-263.

DWORKIN, Ronald. Levando os direitos a sério. Tradução de Nelson Boeira, 2. Ed. São Paulo: Martins Fontes, 2007.

Martins Fontes, 1999.

O império do direito. Tradução Jefferson Luiz Camargo. São Paulo:

Uma questão de princípio. Tradução de Luís Carlos Borges. 2.ed. São

Paulo: Martins Fontes, 2005

ESPÍNDOLA, Angela Araújo da Silveira; CUNHA, Guilherme Cardoso Antunes. O processo, os direitos fundamentais e a transição do estado liberal clássico para o estado contemporâneo. In: Revista de Estudos Constitucionais, Hermenêutica e Teoria do Direito, v. 3, janeiro/junho 2011.

FACCINI NETO, Orlando. Elementos de uma teoria da decisão judicial: hermenêutica, constituição e respostas corretas em direito. Porto Alegre: Livraria do Advogado, 2011.

FERNANDES, Noeli. O TEMPO RAZOÁVEL DE DURAÇÃO DO PROCESSO

E A SOCIEDADE DA URGÊNCIA: A TRANSFORMAÇÃO DA JURISDIÇÃO NO SÉCULO XXI - DO PROCESSO INDIVIDUALISTA AO PROCESSO COLETIVO. São Leopoldo: UNISINOS, 2010. 156 p. Dissertação (Mestrado) - Programa de Pós Graduação em Direito, Universidade do Vale do Rio dos Sinos, 2010.

GARCÍA-PELAYO, Manuel. As transformações do Estado contemporâneo. Rio de Janeiro: Forense, 2009.

GRESTA, Roberta Maia. Segurança jurídica: o edifício de ponta-cabeça arquitetado na exposição de motivos do projeto do novo código de processo civil brasileiro. In: Jurisdição e processo: tributo ao constitucionalismo. Org. de Márcio Ricardo Staffen e Elaine Harzheim Macedo. Belo Horizonte: Ed. Arraes, 2012.

ISAÍA, Cristiano Becker. Processo Civil e Hermenêutica: a crise do procedimento ordinário e o redesenhar da jurisdição processual pela sentença (democrática) liminar de mérito. Curitiba: Juruá, 2012.

ISAIA, Cristiano Becker; HOFFMAN, Fernando. A jurisdição processual civil no Estado Democrático de Direito: verdades universais ou respostas corretas? In: Revista de Direito Brasileira, v. 3, p. 157-176, 2012. 

em rede

Cristiano Becker Isaia Danielli Gadenz Letícia De La Rue Almeida DOI 10.12957/dep.2014.6922

LUCAS, Doglas Cesar. A crise funcional do Estado e o cenário da jurisdição desafiada. In: MORAIS, José Luiz Bolzan de. O Estado e suas crises. Porto Alegre: Livraria do Advogado, 2005.

MOTTA, Cristina Reindolff da. A motivação das decisões cíveis: como condição de possibilidade para resposta correta/adequada. Porto Alegre: Livraria do Advogado Editora, 2012.

NUNES, Dierle José Coelho. Processo jurisdicional democrático: uma análise crítica das reformas processuais. Curitiba: Juruá, 2009.

OST, François. Júpiter, Hércules, Hermes: Tres modelos de juez. In: Doxa: Cuadernos de Filosofia del Derecho, no 14, 1993. p. 169-194 .Tradução de Isabel Lifante Vidal. Disponível em:

<http://bib.cervantesvirtual.com/servlet/SirveObras/public/01360629872570728587891/cu aderno14/doxa14_11.pdf?portal=4>. Acesso em: 05 jul. 2013.

PÉREZ LUÑO, Antonio-Enrique.Los derechos humanos en la sociedad tecnológica. Madrid: Editorial Universitas, 2012.

PICARDI, Nicola. Jurisdição e processo. Tradução e organização de Carlos Alberto Alvaro de Oliveira. Rio de Janeiro: Ed. Forense, 2008.

PORTO, Pedro Rui da Fontoura. Direitos Fundamentais Sociais: considerações acerca da legitimidade política e processual do Ministério Público e do sistema de justiça para sua tutela. Porto Alegre: Livraria do Advogado Editora, 2006.

SGARBI, Adrian. Clássicos de Teoria do Direito. 2. ed. rev. amp. Rio de Janeiro: Editora Lumen Juris, 2009.

SILVA, Ovídio A. Baptista da. Jurisdição e execução na tradição romano-canônica. 2 a edição. São Paulo: Ed. RT, 1997.

Janeiro: Forense, 2004.

Processo e ideologia: o paradigma racionalista. Rio de

STRECK, Lênio. Verdade e Consenso: constituição, hermenêutica e teorias discursivas. 4. ed. São Paulo: Saraiva, 2011 